\title{
Suberin goes genomics: use of a short living plant to investigate a long lasting polymer
}

\section{Rochus Benni Franke*, Isabel Dombrink and Lukas Schreiber}

Department of Ecophysiology of Plants, Institute of Cellular and Molecular Botany, University of Bonn, Bonn, Germany

Edited by:

Andreas P. M. Weber, University of

Duesseldorf, Germany

\section{Reviewed by:}

Frédéric Domergue, Université

Bordeaux Ségalen, France

Fred Beisson, Centre National de la

Recherche Scientifique, France

*Correspondence:

Rochus Benni Franke, Department of Ecophysiology of Plants, Institute of

Cellular and Molecular Botany,

University of Bonn, Kirschallee 1,

D-53115 Bonn, Germany.

e-mail: rochus.franke@uni-bonn.de
Suberin is a highly persistent cell wall polymer, predominantly composed of long-chain hydroxylated fatty acids. Apoplastic suberin depositions occur in internal and peripheral dermal tissues where they generate lipophilic barriers preventing uncontrolled flow of water, gases, and ions. In addition, suberization provides resistance to environmental stress conditions. Despite this physiological importance the knowledge about suberin formation has increased slowly for decades. Lately, the chemical characterization of suberin in Arabidopsis enabled the proposal of genes required for suberin biosynthesis such as $\beta$-ketoacyl-CoA synthases (KCS) for fatty acid elongation and cytochrome P450 oxygenases (CYP) for fatty acid hydroxylation. Advantaged by the Arabidopsis molecular genetic resources the in silico expression pattern of candidate genes, concerted with the tissue-specific distribution of suberin in Arabidopsis, led to the identification of suberin involved genes including KCS2, CYP86A1, and CYP86B1. The isolation of mutants with a modified suberin composition facilitated physiological studies revealing that the strong reduction in suberin in cyp86a1 mutants results in increased root water and solute permeabilities. The enhanced suberin 1 mutant, characterized by twofold increased root suberin content, has increased wateruse efficiency and is affected in mineral ion uptake and transport. In this review the most recent findings on the biosynthesis and physiological importance of suberin in Arabidopsis are summarized and discussed.

Keywords: suberin, endodermis, Casparian band, $\omega$-hydroxy acids, stress tolerance

\section{INTRODUCTION}

Suberin is an apoplastic biopolymer deposited during secondary cell wall differentiation in specialized plant tissues. The bestknown occurrence of suberin is the periderm of Quercus suber, the cork oak tree. This tissue at the interface between the plant and the environment consists to more than $50 \%$ of suberin (Graça and Pereira, 2000). As indicated by the long shelf live of cork stoppers, the apoplastic deposition of suberin protects polysaccharide cell walls from decomposition. Therefore suberized cell walls are the most persistent plant components of composting tree barks in soil (Kolattukudy, 2001). The unique insulation properties of cork resemble the physiological importance of suberin in plants. The apoplastic incrustation with the lipophilic suberin polymer turns generic, hydrophilic plant cell walls into diffusion barriers for water, gases, and solutes.

Generally suberin is present in cell walls of the root endodermis and hypodermis (Enstone et al., 2003). In a primary developmental state of the endodermis and in most plants also the exodermis, suberin can be present in Casparian bands (CB), the very localized structural modifications of the radial cell walls that reduce the apoplastic transport in and out of the stele (Schreiber et al., 1999; Schreiber and Franke, 2011). In the secondary developmental state

Abbreviations: CB, Casparian bands; Diacids, $\alpha, \omega$-dicarboxylic acids; FAE, fatty acid elongation; FAR, fatty acyl reductase; GPAT, glycerol-3-phosphate acyltransferase; P450, Cytochrome P450 monooxygenases. a suberin lamella is deposited all around the exo- and endodermal cell wall which then forms a barrier also restricting the symplastic transport of water and solutes (Schreiber, 2010; Ranathunge et al., 2011). In addition, the widespread occurrence of suberin also includes none-cutinized aboveground plant-environmentinterfaces such as periderms, the seed coat, and wound healing tissues (Kolattukudy, 2001).

\section{MACROMOLECULE CHEMISTRY}

Suberin in cell walls is insoluble and can therefore not be isolated without modification, which limits our understanding of the polymer in situ. A lot of what we know about the chemistry of suberin, and also what we assume about the suberin macromolecule, is based on the "most logic assembly" of the components found in suberin depolymerisates of destructive protocols with certain specificity. These suberin analysis methods have only been adapted to Arabidopsis in 2005 (Franke et al., 2005), opening the doors for molecular genetic approaches in suberin research in this model species. Based on such compositional analyses suberin can be chemically described as an biopolyester mainly comprised of $\omega$-hydroxy acids and $\alpha, \omega$-dicarboxylic acids (diacids) and lower amounts of fatty acids and alcohols; ranging in carbon chain length from C16 to C32 (C24 in Arabidopsis). Glycerol and minor amounts of aromatic phenylpropanoids are also part of the aliphatic suberin polyester (Franke et al., 2005; Franke and Schreiber, 2007; Graça and Santos, 2007; Graça, 2009; Li-Beisson et al., 2010). The association of this polyester with 
aromatic polymers in periderms and the confirmation of linkages to phenolic units has also led to the tentative model that suberin is a heterogeneous polymer of polyaliphatic and polyaromatic domains (Kolattukudy, 2001; Bernards, 2002; Mattinen et al., 2009). A direct linkage of these two components is an ongoing discussion since aliphatic polyester and polyaromatic domain polymers can only be analyzed separately. If not mentioned otherwise, in this review the authors refer to suberin as the aliphatic polyester since knowledge about synthesis and function of this fraction has significantly advanced in the recent years.

\section{BIOCHEMICAL DIFFICULTIES FAVOR MOLECULAR GENETIC STUDIES}

Based on the monomeric composition of mostly oxygenated fatty acid derivatives with various chain lengths it was evident that key steps in suberin monomer biosynthesis include fatty acid elongation (FAE), $\omega$-hydroxylation, diacid formation, and aromatic component synthesis (For a recent pathway model see http://aralip.plantbiology.msu.edu/pathways/suberin_synthesis_ transport). Only a few biochemical approaches have been reported in the past four decades. Nevertheless, they provided significant allusions to enzymes of the suberin biosynthetic machinery. Cytochrome P450 monooxygenases (P450), oxidoreductase, FAE, and peroxidase activities involved in fatty acid $\omega$-hydroxylation, diacid formation, FAE, and aromatic compound polymerization respectively, were detectable in polyester forming tissues of various none model species (Agrawal and Kolattukudy, 1977; Soliday and Kolattukudy, 1977; Razem and Bernards, 2003; Schreiber et al., 2005c). However, these studies in bean, potato, and corn did not succeed in the isolation and final characterization of defined reactions in suberin pathways. Reasons for the limited progress of biochemical approaches include the tissue-specific distribution of suberin in scarce tissues limiting source material and the membrane associated localization of involved enzyme activities and multi enzyme complexes. In addition, potential substrates for in vitro assays such as very-long-chain oxygenated fatty acids are not commercially available.

\section{CORRELATIONS BETWEEN SUBERIZATION AND PHYSIOLOGICAL PARAMETERS}

The application of micromanipulating sampling techniques targeting suberized tissue and sophisticated compositional analysis methods to investigate root suberization in the late 1990s (Schreiber et al., 1999) allowed to quantitatively describe differences in tissue-specific suberization between species (Schreiber et al., 2005b), as well as upon environmental conditions (Zimmermann et al., 2000; Schreiber et al., 2005a). Such studies in rice revealed that $\mathrm{CB}$ formation and deposition of lamellar suberin in the root exodermis is significantly enhanced under environmental stress conditions such as salt stress (Krishnamurthy et al., 2009) or oxygen deficiency (Kotula et al., 2009). Furthermore, the increasing root suberin content negatively correlated with the accumulation and transport of sodium into shoots (Krishnamurthy et al., 2009, 2011). A similar quantitative relation was established between the increasing exodermal suberin content along the root axis and decreasing radial oxygen loss (Kotula et al., 2009).
The above examples represent only a compendium of multiple correlative evidences that quantitative differences in exodermal or endodermal suberin impact the permeability of water and solutes across roots in the adaptations to oxygen, salt, and drought stress (Ranathunge et al., 2011). However, care should be exercised in the evaluation of the "contribution" of suberin to the observed physiological effects when interpreting physiological parameters and cell wall modifications upon extreme culture conditions. Based on transcriptomic studies it can easily be imagined that modified culture conditions result in a comprehensive reprogramming of gene expression and metabolism (Kilian et al., 2007). Therefore physiological adaptations to unfavorable conditions are not necessarily directly related to suberin only. To gain more insides into the physiological importance of suberin in stress tolerance and the relation between suberin chemistry and permeability, plants are required in which only suberin is modified. An increased knowledge about suberin biosynthesis and deposition to specifically modify suberin, e.g., in mutants and transgenic plants, is a key to investigate functional effects and physiological parameters without background effects due to varied growth conditions, developmental stage, or species used in a study.

\section{FUNCTIONAL GENOMICS FACILITATED THE IDENTIFICATION OF KEY FACTORS IN SUBERIN MONOMER BIOSYNTHESIS}

Molecular genetic approaches in the previously used "suberin model species" such as the long live circle tree Q. suber and the polyploid potato were strongly limited since targeted mutagenesis, mapping, and reverse genetics are rather generation spanning projects in these species. Consequently, Arabidopsis with the wealth of genomic resources got increasing attention in suberin research after the distribution and chemistry of suberin had been characterized in this short living model species (Franke et al., 2005). As most suberin detection methods are laborious and/or plant lethal, high throughput forward screens are disadvantages favoring reverse genetic approaches. One strategy was the short listing of candidate genes potentially involved in fatty acid oxygenation, elongation, or conjugation based on transcript abundance in tissues undergoing suberization. Community serving, large scale expression studies generating publicly available transcriptomic sets with high developmental-, organ-, and tissue-specific resolutions (Birnbaum et al., 2003; Brady et al., 2007; Kilian et al., 2007) greatly facilitated the selection of potential suberin biosynthetic genes out of multimember families.

The $\omega$-hydroxylation of fatty acids, required to produce the predominant suberin monomers, is typically catalyzed by P450s (Pinot and Beisson, 2011), a family of proteins represented by 272 genes in the Arabidopsis genome (Schuler et al., 2006). Transcriptomic data sets have been screened for root expression and among the top 50 root expressed P450, members of the CYP86 and CYP94 subfamily were identified (Figure 1). These sub families are known to catalyze fatty acid $\omega$-hydroxylation in plants (Kandel et al., 2006). Recombinant CYP86A1 was previously characterized as the first C16 and C18 fatty acid $\omega$-hydroxylase from plants (Benveniste et al., 1998). However, only the characterization of the corresponding horst mutant 10 years later revealed the biological process CYP86A1/HORST is involved. Detailed expression studies using promoter:reporter fusions showed that CYP86A1/HORST 


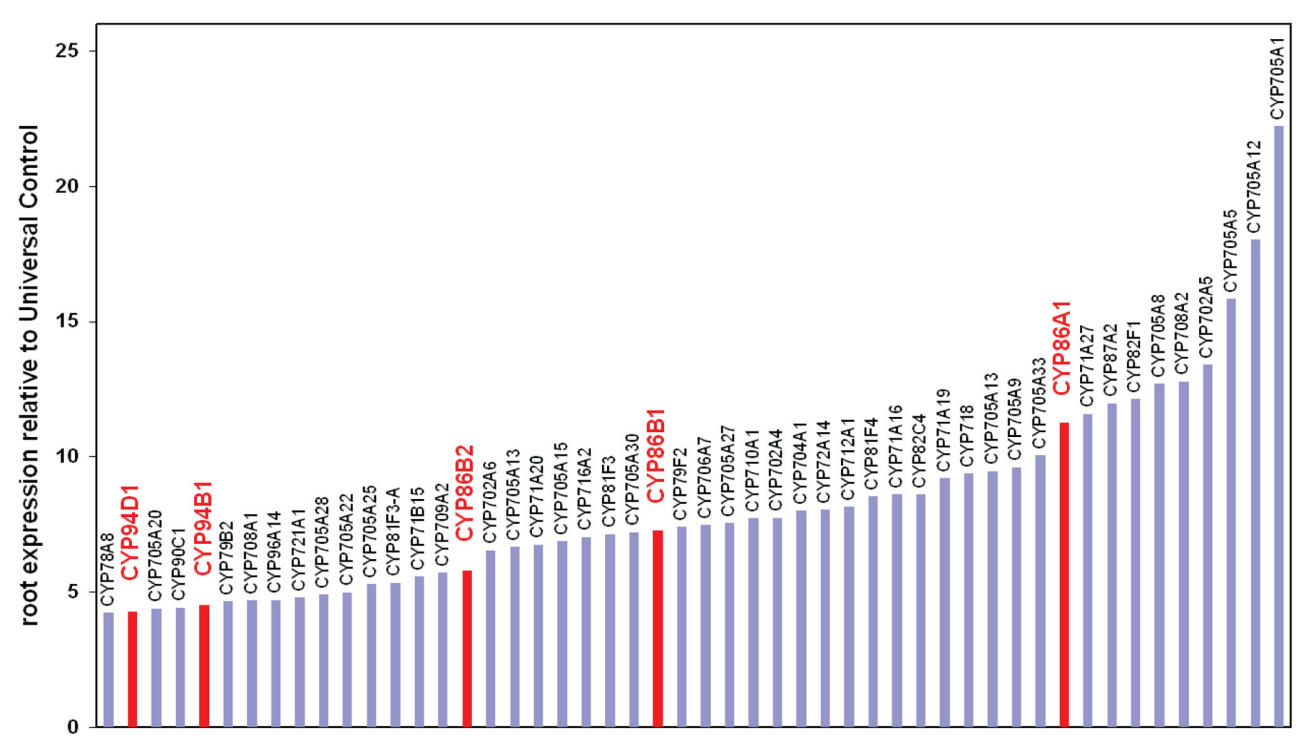

FIGURE 1 | Expression level of the $\mathbf{5 0}$ most highly root expressed Arabidopsis P450. Data were extracted from online published results of NSF 2010 project (0115068) "Functional genomics of P450s" (http://arabidopsis-p450.biotec.uiuc.edu). Expression values are normalized relative to a universal control created from a control RNA pool derived from all aerial tissues and roots. Putative $\omega$-hydroxylases are indicated in red. is specifically expressed in the roots, in particular in the endodermis, the suberized tissue of roots (Höfer et al., 2008). The compositional suberin analysis of cyp86a1/horst mutant roots demonstrated the involvement in suberin biosynthesis. Consistent with the catalytic function of the recombinant CYP86A1/HORST protein, $\mathrm{C} 16$ and $\mathrm{C} 18$ oxygenated fatty acids are strongly reduced in cyp86a1/horst suberin, resulting in a 60\% reduction in total root suberin (Li et al., 2007; Höfer et al., 2008). Translational fusions of CYP86A1 with GFP demonstrated that bulk parts of suberin biosynthesis are taking place at the endoplasmic reticulum.

Subsequently, the CYP86B1 was characterized to have a very similar expression pattern in the root endodermis (Compagnon et al., 2009). In the corresponding ralph mutant the effect on total suberin was not significant, but a pronounced monomer specific effect was determined. Very-long-chain $\omega$-hydroxy acids and diacids, specifically of carbon chain length C22 and C24, were almost completely lacking in root suberin as well as in the seed coat (Compagnon et al., 2009; Molina et al., 2009). In RNAi lines these chain-length-specific phenotypes correlated with the partially decreased CYP86B1/RALPH expression levels, further demonstrating that CYP86B1 is required for $\geq C 22 \omega$-oxygenated fatty acids in suberin. The depletion in very-long-chain oxygenated fatty acids was compensated by an increase in C22 and C24 acids in approximately stoichiometric amounts. Although many attempts to characterize the recombinant enzyme failed these compositional data strongly suggest that CYP86B1/RALPH encodes a very-long-chain specific fatty acid $\omega$-hydroxylase uncovered in plants before. Furthermore, the replacement of bifunctional fatty acids by monofunctional fatty acids in the cyp86b1/ralph suberin polyester clearly indicates that suberin structure needs more investigation. As discussed by Molina et al., 2009, a large fraction of monofunctional monomers should preclude an extended or cross-linked aliphatic polymer, since monofunctional fatty acids terminate the ester polymer chain. Thus yet unidentified components are required to describe the suberin macromolecular structure.

One chemical difference between the aliphatic polyesters cutin and suberin is the occurrence of very-long-chain monomers in suberin compared to the C16 and C18 dominated cutin (Franke et al., 2005; Pollard et al., 2008). Therefore another molecular target in suberin biosynthesis is FAE. $\beta$-ketoacyl-CoA synthases (KCS) are the key enzymes in this process (Joubès et al., 2008). The much smaller KCS gene family seemed to be suitable to identify the suberin candidates amongst the 21 Arabidopsis KCS by a systematic characterization of the gene family, as intended in the Arabidopsis 2010 initiative. Unfortunately, molecular genetic and biochemical studies revealed broad overlaps in both enzymatic function and expression pattern, which slowed down the short listing of KCS candidate genes. Only three C2-extending FAE-cycles are required to provide the carbon backbone of the "longest" (C24) Arabidopsis suberin monomers, but at least seven KCS are characterized by a strong expression in roots (Figure 2; Joubès et al., 2008). Further more, at least five Arabidopsis KCS have been demonstrated to be able to participate in the elongation to C22 (Trenkamp et al., 2004; Blacklock and Jaworski, 2006; Paul et al., 2006), the predominant very-long-chain monomers in Arabidopsis root suberin. Nevertheless, KCS2/DAISY and KCS20 were identified to be involved in suberin formation. The only moderate chemical phenotypes in the corresponding mutants (Franke et al., 2009; Lee et al., 2009) might reflect the above redundancy. The minor but significant suberin changes could also indicate that mutations in the above KCS, which could also be involved in other processes requiring very-long-chain fatty acids (e.g., membrane lipids), secondarily affect the fatty acid pool for suberin monomer biosynthesis. 


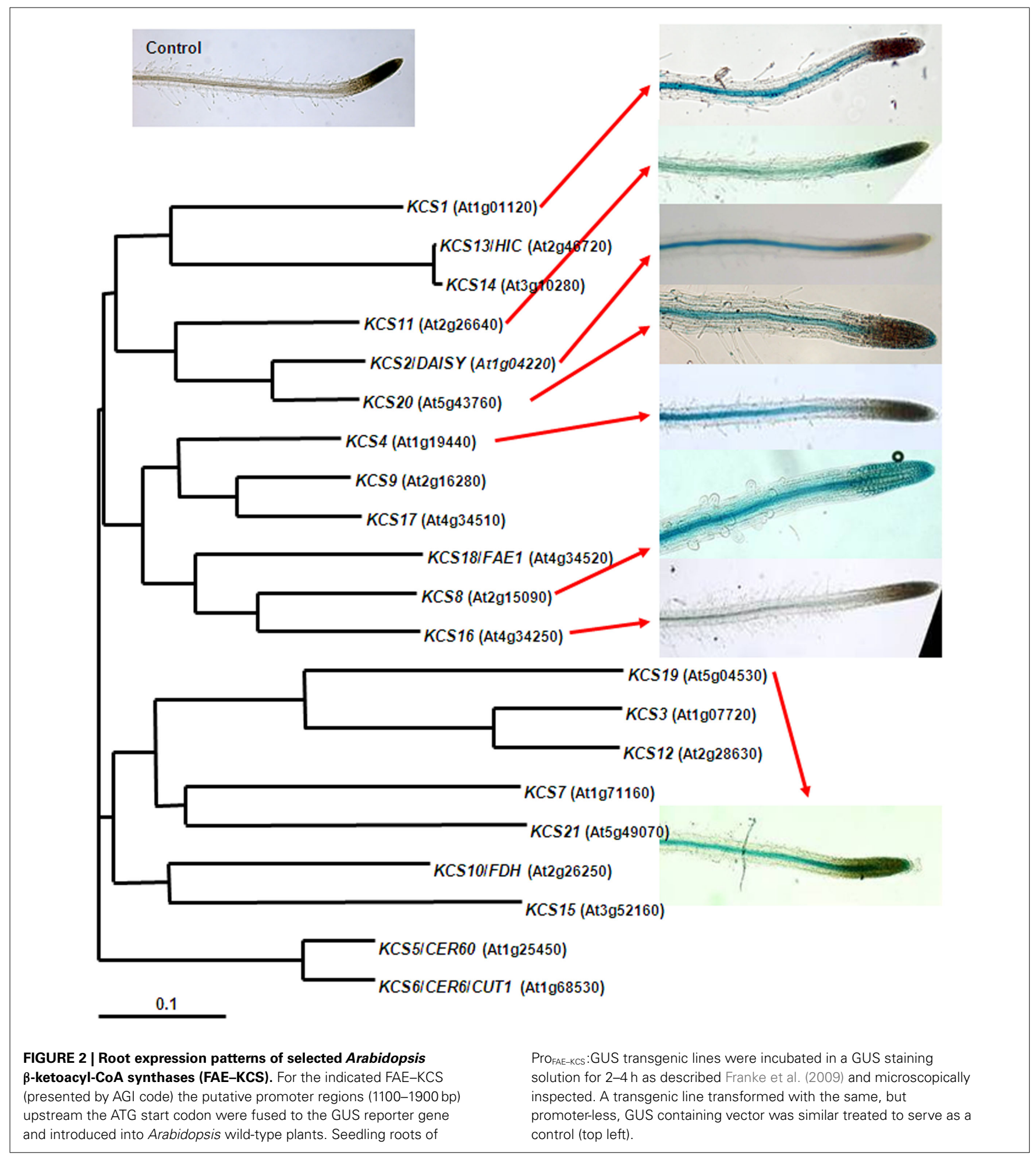

Similar to the P450 above, also GPAT5, the first gene identified in suberization, is expressed in the root endodermal tissue (Beisson et al., 2007). The detailed characterization of the gpat5 mutants revealed that the encoded glycerol-3-phosphate acyltransferase is involved in the formation of C22 and C24 very-long-chain oxygenated suberin monomers in roots and also in the seed coat.
Furthermore, extractable C22/C24 monoacylglycerols and very long-chain alkyl hydroxycinnamate esters, designated root waxes in dependence of suberin associated peridermal waxes, are also reduced in gpat5 mutant roots indicating a central role of GPAT5 in the biosynthesis of extractable and polymer bound extracellular lipids. Different from sn-1 acylation by GPATs in the metabolic 
pathways of membrane and storage lipid biosynthesis, GPAT5 catalyzes the sn-2 acylation of glycerol (Yang et al., 2010). In the biochemical characterization of related proteins, sn-2 acylation was exclusively found for GPATs involved in extracellular polyester biosynthesis. Therefore and due to the absence of GPATs with sn-2 acylation related domains in animals, microorganism, and algae, sn-2 acylation is hypothesized to be associated with land plant evolution (Yang et al., 2010).

The continuing expansion and cross-linking of Arabidopsis resources enabled the development and employment of comprehensive bioinformatics tools including the generation and analysis of transcriptional networks. The use of the above suberin genes to deduce such networks resulted in the successful isolation of new coexpressed suberin involved genes such as fatty acyl reductases (FAR1, FAR4, FAR5; Domergue et al., 2010) and a feruloyl transferase ASFT (Molina et al., 2009), the latter representing the first gene required for aromatic suberin constituents.

A very nice example of synergistic effects due to the employment of the same model species is the characterization of the first enhanced suberin mutant esb1 (Baxter et al., 2009). Esb1 was identified in a forward screen for changes in the leaf ion composition and described as being reduced in $\mathrm{Ca}, \mathrm{Mn}$, and $\mathrm{Zn}$. Crafting experiments revealed that the root determines the leaf ionome phenotype. After the gene was identified it turned out to be expressed in the endodermis pointing to a potential involvement in suberization. The root suberin analysis revealed that all suberin monomers are more or less equally increased, resulting in a twofold total suberin content in esb1 roots.

\section{PHYSIOLOGICAL APPROACHES INVESTIGATING THE ROLE OF SUBERIN IN ARABIDOPSIS}

In the last 4 years an array of mutants originated to start looking into the physiological consequences of quantitative (cyp86a1/horst, esb1) and/or qualitative (gpat5, cyp86b1/ralph, kcs2/daisy, kcs20, far1, far4, far5, asft/hht) suberin modifications (Ranathunge et al., 2011). More or less specific evaluations of the permeability of plant environment interfaces included "whole plant assays" of the fitness during the culture period. In our hands the chemically moderate suberin mutants $k c s 2 /$ daisy and cyp86b1/ralph, as well as the severely suberinreduced cyp86a1/horst mutant, showed no obvious growth or developmental phenotypes under the "optimized" growth chamber conditions as well as under salt stress. This could indicate that compositionally modified suberin ( $k c s 2 /$ daisy, cyp86b1/ralph) and small amounts of suberin (cyp86al/horst) are sufficient to provide wild-type-like functional properties. However it cannot be excluded that physiological adaptations modifying the water and solute balance during the long term soil culturing have compensated for potential barrier changes by "disorganized" root suberin. In this context is worth mentioning that gpat5 seedlings with also moderate changes in very-long-chain suberin monomers are more sensitive toward high salt conditions when grown on agar plates (Beisson et al., 2007). Furthermore, germination rate and seedling establishment under high salt conditions is decreased in the two seed suberin affected mutants gpat5 and asft/hht, indicating that the ion permeability of the seed coat and primary root is affected (Beisson et al., 2007; Gou et al., 2009). This was confirmed in a more direct assay showing a significantly increased diffusion of a tetrazolium dye into the seeds of gpat5 and asft/hht. Although this indicates a reduced diffusion resistance of the seed surface a quantitative assessment of permeability across suberized tissue was not possible using above assay.

Effects on the permeability of water and solutes across roots were investigated in a quantitative manner using decaptured whole root systems, positively and negatively pressurized in the root pressure probe (Ranathunge and Schreiber, 2011). A significantly faster pressure equalization - indicative for whole root permeability - after application of hydrostatic and osmotic pressures to pressure-probe-connected roots was determined in the $60 \%$ suberin-reduced cyp86a1/horst mutant. In contrast to previously determined negative correlations between the suberin content and root permeability, only very minor effects on water and solute permeability were observed in $e s b 1$ roots using the pressure probe. This indicates that additional suberization does not necessarily result in a strongly increased resistance to the effected water and solute flows. Probably other factors than suberin amount contribute to the lower limit for permeability across the whole root under the applied pressure conditions. Suberin polymer ultrastructure and submicroscopical root anatomical features (e.g., cell wall pores) could be considered as such factors for further investigations.

Whole plant stress experiments revealed a pronounced drought tolerance for the esb1 mutant (Figure 3). Whether this is a direct consequence of the increased suberin content limiting the backflow of water from the plant to the dry rhizosphere or an indirect effect of physiological adaptations improving the water-use efficiency due to enhanced suberin barriers needs to be investigated. Nevertheless the esbl characterization provided the first genetic evidence for the role of suberin in water balance and translocation of ions to the shoot (Baxter et al., 2009). This is further supported by the recently identified mutant in sphingolipid metabolism showing suberin phenotypes accompanied by changes in the leaf ionome (Chao et al., 2011).

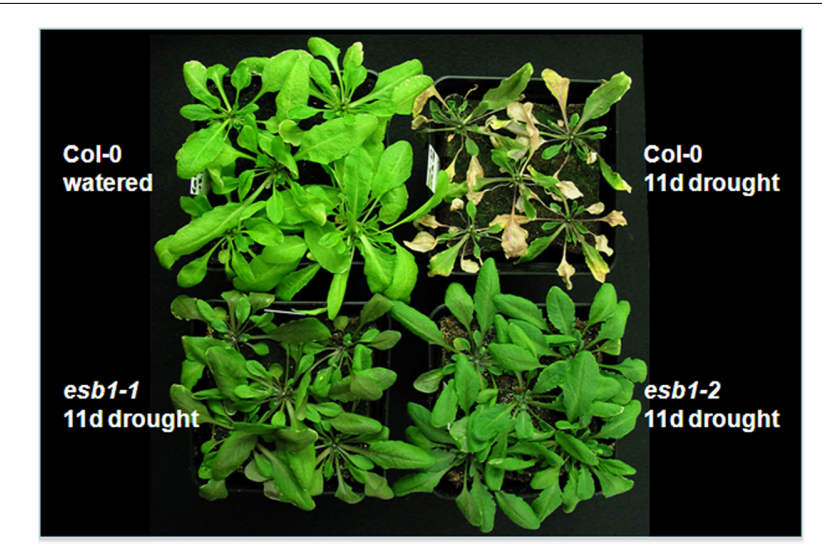

FIGURE 3 | Drought tolerance in the enhanced suberin 1 (esb1) mutant. Arabidopsis wild-type plants and two allelic esb1 mutants were cultured in soil for 3 weeks with regular irrigation. Subsequently watering was discontinued. Plants were recorded 11 days after water withdrawal. A wild-type without water withdrawal served as a control (Upper left). 


\section{CHALLENGES AND PERSPECTIVES}

Although suberin biosynthetic pathways have been suggested for decades, only the very recent reverse genetics approaches in Arabidopsis allowed the definite identification of genes encoding various enzymatic activities in suberin formation. As outlined above, many key players in the biosynthesis of suberin monomers have been identified in the past 4 years. The sequential order of reactions is currently under investigation and discussion (Pollard et al., 2008). Future challenges include the elucidation of subsequent steps in apoplastic suberin formation such as export and assembly of precursors. The list of candidates in recent models include ABC-transporters, lipid transfer proteins, lipases, and oxidases (Li-Beisson et al., 2010). From a structural point of view it will be challenging to determine the intramolecular linkages. This and the discovery of intermolecular linkages could provide hints of whether suberin macromolecular structure affects barrier properties and whether suberin is immobilized in the cell wall by "molecular entanglement" or distinct covalent linkages to other structural cell wall polymers. Very recently the first gene required for aromatic suberin components, $A S F T / H H T$, has been identified (Gou et al., 2009; Molina et al., 2009). Although ASFT/HHT has only been investigated for the contribution to the suberin polyester domain, the recent success in molecular genetic approaches let us expect the identification of more players in aromatic suberin biosynthesis possibly including genes required for polyphenolic cell wall components. This will allow us to verify and, if present, investigate in Arabidopsis the composition, structure, linkages, and importance of a polyaromatic domain often associated with the aliphatic polyester domain and previously mostly studied in the much slower developing potato.

The increased water and solute permeability in cyp86a1/horst roots and the linkage between root suberin and leaf ionome also points to the requirement of a higher spatial resolution in the localization of the suberin containing root modifications providing the ion selectivity in the roots. As mentioned above $\mathrm{CB}$ provide a resistance to the apoplastic path of water and dissolved molecules across the root. This can be visualized by soluble dyes or fluorescing molecules such as propidium iodide. Propidium iodide movement into the vascular system is blocked at the position of CB (Alassimone et al., 2010). The compounds in the CB that are

\section{REFERENCES}

Agrawal, V. P., and Kolattukudy, P. E. (1977). Biochemistry of suberization: $\omega$-hydroxy acid oxidation in enzyme preparations from suberizing potato tuber disks. Plant Physiol. 59, 667-672.

Alassimone, J., Naseer, S., and Geldner, N. (2010). A developmental framework for endodermal differentiation and polarity. Proc. Natl. Acad. Sci. U.S.A. 107, 5214-5219.

Baxter, I., Hosmani, P. S., Rus, A., Lahner, B., Borevitz, J. O., Muthukumar, B., Mickelbart, M. V., Schreiber, L., Franke, R. B., and Salt, D. E. (2009). Root suberin forms an extracellular barrier that affects water relations and mineral nutrition in Arabidopsis. PLoS Genet. 5, e1000492. doi: 1000410.1001371/ journal.pgen.1000492.

Beisson, F., Li, Y. H., Bonaventure, G., Pollard, M., and Ohlrogge, J. B. (2007). The acyltransferase GPAT5 is required for the synthesis of suberin in seed coat and root of Arabidopsis. Plant Cell 19, 351-368.

Benveniste, I., Tijet, N., Adas, F., Philipps, G., Salaün, J. P., and Durst, F. (1998). CYP86A1 from Arabidopsis thaliana encodes a cytochrome P450-dependent fatty acid $\omega$-hydroxylase. Biochem. responsible for this barrier properties are a matter of debate. In corn, suberin represents a reasonable candidate as $\mathrm{CB}$ in the primary stage endodermis react positive in the histochemical suberin staining using Sudan Red (Schreiber et al., 1999). In Clivia miniata where it is possible to mechanically isolate CB it could be shown that they contain substantial amounts of lignin-like phenolics and rather small amounts of aliphatic suberin. Unfortunately in both species it is not reasonable to target $\mathrm{CB}$ formation by molecular tools. Instead, progress can be expected using Arabidopsis since very recently the first gene involved in $\mathrm{CB}$ formation has been identified in this model plant (Roppolo et al., 2011). This has been possible by extended analysis of tissue-specific transcriptomic data in combination with genome wide analysis of intracellular targeting sequences, tools which are best available for Arabidopsis. Upcoming CB mutants and the molecular dissection of CB formation will help to understand the chemical composition of $\mathrm{CB}$ and will provide the opportunity to further look into the physiological importance of CB in water relation and ion permeability.

The esb1 drought and ion phenotypes demonstrates the potential of modifying plant nutrition and improving stress tolerance by modifying the degree of suberization also in agronomical important species. The transfer of knowledge to crop plants has successfully been demonstrated in potato. The recently identified potato genes CYP86A33, StKCS6, and FHT are the orthologs of previously characterized Arabidopsis genes. Silencing of these potato genes resulted in chemical modifications of tuber periderm suberin, accompanied by changes in the peridermal water permeability (Serra et al., 2009a,b, 2010). The potential for similar translational research has greatly increased in the past since genomes for rice, potato, and other crops species are available and advanced sequencing techniques initiated systematic genome and transcriptome analyses in a variety of species including cork oak (Paiva et al., 2011). The recent and future pioneering findings in Arabidopsis will continuously pave the road for successful suberin research in such species.

\section{ACKNOWLEDGMENTS}

This work was funded by the DFG grant FR 1721/1-1 within the framework of the Arabidopsis Functional Genomics Network (AFGN). 
Compagnon, V., Diehl, P., Benveniste, I., Meyer, D., Schaller, H., Schreiber, L., Franke, R., and Pinot, F. (2009). CYP86B1 is required for very long chain $\omega$-hydroxy acids and $\alpha, \omega$-dicarboxylic acids synthesis in root and seed suberin polyester. Plant Physiol. 150, 1831-1843.

Domergue, F., Vishwanath, S. J., Joubès, J., Ono, J., Lee, J. A., Bourdon, M., Alhattab, R., Lowe, C., Pascal, S., Lessire, R., and Rowland, O. (2010). Three Arabidopsis fatty acyl-CoA reductases, FAR1, 2 FAR4, and FAR5, generate primary fatty alcohols associated with suberin deposition. Plant Physiol. 153, 1539-1554.

Enstone, D. E., Peterson, C. A., and Ma, F. (2003). Root endodermis and exodermis: structure, function, and responses to the environment. J. Plant Growth Regul. 21, 335-351.

Franke, R., Briesen, I., Wojciechowski, T., Faust, A., Yephremov, A., Nawrath, C., and Schreiber, L. (2005). Apoplastic polyesters in Arabidopsis surface tissues - a typical suberin and a particular cutin. Phytochemistry 66, 2643-2658.

Franke, R., Höfer, R., Briesen, I., Emsermann, M., Efremova, N., Yephremov, A., and Schreiber, L. (2009). The DAISY gene from Arabidopsis encodes a fatty acid elongase condensing enzyme involved in the biosynthesis of aliphatic suberin in roots and the chalaza-micropyle region of seeds. Plant J. 57, 80-95.

Franke, R., and Schreiber, L. (2007). Suberin - a biopolyester forming apoplastic plant interfaces. Curr. Opin. Plant Biol. 10, 252-259.

Gou, J. Y., Yu, X. H., and Liu, C. J. (2009). A hydroxycinnamoyltransferase responsible for synthesizing suberin aromatics in Arabidopsis. Proc. Natl. Acad. Sci. U.S.A. 106, 18855-18860.

Graça, J. (2009). Hydroxycinnamates in suberin formation. Phytochem. Rev. 9, 85-91.

Graça, J., and Pereira, H. (2000). Methanolysis of bark suberins: analysis of glycerol and acid monomers. Phytochem. Anal. 11, 45-51.

Graça, J., and Santos, S. (2007). Suberin: a biopolyester of plants' skin. Macromol. Biosci. 7, 128-135.

Höfer, R., Briesen, I., Beck, M., Pinot, F., Schreiber, L., and Franke, R. (2008). The Arabidopsis cytochrome P450 CYP86A1 encodes a fatty acid $\omega$-hydroxylase involved in suberin monomer biosynthesis. J. Exp. Bot. 59, 2347-2360.
Joubès, J., Raffaele, S., Bourdenx, B., Garcia, C., Laroche-Traineau, J., Moreau, P., Domergue, F., and Lessire, R. (2008). The VLCFA elongase gene family in Arabidopsis thaliana: phylogenetic analysis, 3D modelling and expression profiling. Plant Mol. Biol. 67, 547-566.

Kandel, S., Sauveplane, V., Olry, A., Diss, L., Benveniste, I., and Pinot, F. (2006). Cytochrome P450dependent fatty acid hydroxylases in plants. Phytochem. Rev. 5, 359-372.

Kilian, J., Whitehead, D., Horak, J., Wanke, D., Weinl, S., Batistic, O., Angelo, C., Bornberg-Bauer, E., Kudla, J., and Harter, K. (2007). The AtGenExpress global stress expression data set: protocols, evaluation and model data analysis of UVB light, drought and cold stress responses. Plant J. 50, 347-363.

Kolattukudy, P. E. (2001). "Suberin from plants," in Biopolymers, eds. Y. Doi and A. Steinbüchel (Weinheim: Wiley-VCH), 41-68.

Kotula, L., Ranathunge, K., Schreiber, L., and Steudle, E. (2009). Functional and chemical comparison of apoplastic barriers to radial oxygen loss in roots of rice (Oryza sativa L.) grown in aerated or deoxygenated solution. J. Exp. Bot. 60, 2155-2167.

Krishnamurthy, P., Ranathunge, K., Franke, R., Prakash, H. S., Schreiber, L., and Mathew, M. K. (2009). The role of root apoplastic transport barriers in salt tolerance of rice (Oryza sativa L.). Planta 230, 119-134.

Krishnamurthy, P., Ranathunge, K., Nayak, S., Schreiber, L., and Mathew, M. K. (2011). Root apoplastic barriers block $\mathrm{Na}^{+}$transport to shoots in rice (Oryza sativa L.). J. Exp. Bot. 62, 4215-4228.

Lee, S.-B., Jung, S.-J., Go, Y.-S., Kim, H.-U., Kim, J.-K., Cho, H.-J., Park, O. K., and Shu, M.-C. (2009). Two Arabidopsis 3-ketoacyl CoA synthase genes, KCS20 and KCS2/DAISY, are functionally redundant in cuticular wax and root suberin biosynthesis, but differentially controlled by osmotic stress. Plant J. 60, 462-475.

Li, Y., Beisson, F., Koo, A. J. K., Molina, I., Pollard, M., and Ohlrogge, J. (2007). Identification of acyltransferases required for cutin biosynthesis and production of cutin with suberin-like monomers. Proc. Natl. Acad. Sci. U.S.A. 104, 18339-18344.

Li-Beisson, Y., Shorrosh, B., Beisson, F., Andersson, M. X., Arondel, V., Bates, P. D., Baud, S., Bird, D., Debono, A., Durrett, T. P., Franke, R. B., Graham,
I. A., Katayama, K., Kelly, A. A., Larson, T., Markham, J. E., Miquel, M., Molina, I., Nishida, I., Rowland, O., Samuels, L., Wada, H., Welti, R., Xu, C., Zallot, R., Ohlrogge, J., and Schmid, K. M. (2010). Acyl-lipid metabolism. The Arabidopsis Book 8, e0133. doi: 10.1199/tab.0133

Mattinen, M.-L., Filpponen, I., Järvinen, R., Li, B., Kallio, H., Lehtinen, P. and Argyropoulos, D. (2009). Structure of the polyphenolic component of suberin isolated from potato (Solanum tuberosum var. Nikola). J. Agric. Food Chem. 57, 9747-9753.

Molina, I., Li-Beisson, Y., Beisson, F., Ohlrogge, J. B., and Pollard, M. (2009). Identification of an Arabidopsis feruloyl-coenzyme A transferase required for suberin synthesis. Plant Physiol. 151, 1317-1328.

Paiva, J., Fevereiro, P., Marques, P., Rodrigues, J., Le Provost, G., Plomion, C., Grima-Pettenati, J., Bouchez, O., Klopp, C., Berges, H., and Graça, J. (2011). Deciphering cork formation in Quercussuber. BMC Proc. 5, P172. doi:10.1186/1753-6561-5-S7-P172

Paul, S., Gable, K., Beaudoin, F., Cahoon, E., Jaworski, J., Napier, J. A., and Dunn, T. M. (2006). Members of the Arabidopsis FAE1-like 3-ketoacylCoA synthase gene family substitute for the Elop proteins of Saccharomyces cerevisiae. J. Biol. Chem. 281, 9018-9029.

Pinot, F., and Beisson, F. (2011) Cytochrome P450 metabolizing fatty acids in plants: characterization and physiological roles. FEBS J. 278, 195-205.

Pollard, M., Beisson, F., Li, Y., and Ohlrogge, J. B. (2008). Building lipid barriers: biosynthesis of cutin and suberin. Trends Plant Sci. 13, 236-246.

Ranathunge, K., and Schreiber, L. (2011). Water and solute permeabilities of Arabidopsis roots in relation to the amount and composition of aliphatic suberin. J. Exp. Bot. 62, 1961-1974.

Ranathunge, K., Schreiber, L., and Franke, R. (2011). Suberin research in the genomics era - new interest for an old polymer. Plant Sci. 180, 399-413.

Razem, F. A., and Bernards, M. A. (2003). Reactive oxygen species production in association with suberization: evidence for an NADPHdependent oxidase. J. Exp. Bot. 54, 935-941.

Roppolo, D., De Rybel, B., Tendon, V. D., Pfister, A., Alassimone, J., Vermeer, J. E. M., Yamazaki, M., Stierhof, Y.-D., Beeckman, T., and Geldner, N.
(2011). A novel protein family mediates Casparian strip formation in the endodermis. Nature 473, 380-383.

Schreiber, L. (2010). Transport barriers made of cutin, suberin and associated waxes. Trends Plant Sci. 15, 546-553.

Schreiber, L., Franke, R., and Hartmann, K. (2005a). Effects of $\mathrm{NO}_{3}$ deficiency and $\mathrm{NaCl}$ stress on suberin deposition in rhizo- and hypo-dermal (RHCW) and endodermal cell walls (ECW) of castor bean (Ricinus communis L.) roots. Plant Soil 269, 333-339.

Schreiber, L., Franke, R., and Hartmann, K. (2005b). Wax and suberin development of native and wound periderm of potato (Solanum tuberosum L.) and its relation to peridermal transpiration. Planta 220, 520-530.

Schreiber, L., Franke, R., and Lessire, R. (2005c). Biochemical characterization of elongase activity in corn (Zea mays L.) roots. Phytochemistry 66, 131-138.

Schreiber, L., and Franke, R. B. (2011). "Endodermis and exodermis in roots," in eLS (Chichester: John Wiley \& Sons, Ltd.), doi: 10.1002/9780470015902.a0002086. pub2

Schreiber, L., Hartmann, K., Skrabs, M., and Zeier, J. (1999). Apoplastic barriers in roots: chemical composition of endodermal and hypodermal cell walls. J. Exp. Bot. 50, 1267-1280.

Schuler, M. A., Duan, H., Bilgin, M., and Ali, S. (2006). Arabidopsis cytochrome P450s through the looking glass: a window on plant biochemistry. Phytochem. Rev. 5, 205-237.

Serra, O., Hohn, C., Franke, R., Prat, S., Molinas, M., and Figueras, M. (2010). A feruloyl transferase involved in the biosynthesis of suberin and suberin-associated wax is required for maturation and sealing properties of potato periderm. Plant J. 62, 277-290.

Serra, O., Soler, M., Hohn, C., Franke, R., Schreiber, L., Prat, S., Molinas, M., and Figueras, M. (2009a). Silencing of StKCS6 in potato periderm leads to reduced chain lengths of suberin and wax compounds and increased peridermal transpiration. J. Exp. Bot. 60, 697-707.

Serra, O., Soler, M., Hohn, C., Sauveplane, V., Pinot, F., Franke, R., Schreiber, L., Prat, S., Molinas, M., and Figueras, M. (2009b). CYP86A33-targeted gene silencing in potato tuber alters suberin composition, distorts suberin lamellae, and impairs the periderm's water 
barrier function. Plant Physiol. 149, 1050-1060.

Soliday, C. L., and Kolattukudy, P. E. (1977). Biosynthesis of cutin. $\omega$ Hydroxylation of fatty acids by a microsomal preparation from germinating Vicia faba. Plant Physiol. 59, 1116-1121.

Trenkamp, S., Martin, W., and Tietjen, K. (2004). Specific and differential inhibition of very-long-chain fatty acid elongases from Arabidopsis thaliana by different herbicides. Proc. Natl. Acad. Sci. U.S.A. 101, 11903-11908.
Yang, W., Pollard, M., Li-Beisson, Y., Beisson, F., Feig, M., and Ohlrogge, J. (2010). A distinct type of glycerol-3phosphate acyltransferase with sn-2 preference and phosphatase activity producing 2-monoacylglycerol. Proc. Natl. Acad. Sci. U.S.A. 107, 12040-12045.

Zimmermann, H. M., Hartmann, K., Schreiber, L., and Steudle, E. (2000). Chemical composition of apoplastic transport barriers in relation to radial hydraulic conductivity of corn roots (Zea mays L.). Planta 210, 302-311.
Conflict of Interest Statement: There is no conflict of interest. However I apologize to the colleagues whose equally important achievements and contributions in the field could not be detailed due to the size limitations of this mini review.

Received: 31 October 2011; paperpending published: 14 November 2011; accepted: 03 January 2012; published online: 31 January 2012.

Citation: Franke RB, Dombrink I and Schreiber L (2012) Suberin goes genomics: use of a short living plant to investigate a long lasting polymer. Front. Plant Sci. 3:4. doi: 10.3389/fpls.2012.00004

This article was submitted to Frontiers in Plant Physiology, a specialty of Frontiers in Plant Science.

Copyright (C) 2012 Franke, Dombrink and Schreiber. This is an open-access article distributed under the terms of the Creative Commons Attribution Non Commercial License, which permits noncommercial use, distribution, and reproduction in other forums, provided the original authors and source are credited. 